\title{
The Study of English Curriculum at Secondary Level for Developing Critical Thinking
}

\author{
Dr. Asifa Qasim¹, Muhammad Ajmal2,*, Tanzeela Azam³ \\ ${ }^{1}$ Department of English Language and Translation, College of Arabic and Social Studies, \\ Qassim University, Saudi Arabia \\ ${ }^{2}$ Assistant Professor, Department of English, Faculty of Language and Literature, \\ University of Lahore, Pakistan \\ ${ }^{3}$ M.Phil Scholar, Faculty of Language and Literature, University of Lahore, Sargodha \\ Campus, Pakistan
}

\begin{abstract}
The original input of this study involves in creating a critical thinking structure that can be used to explore the elements of critical thinking in the textbooks. The teachers, who are concerned with the improvement of students' critical thinking skills, can also use this structure as a guideline. This study attempts to find out the extent to which critical thinking has been manifested in the two selected English textbooks, Punjab Textbook Board (PTB) and Oxford Progressive English (OPE) taught at secondary level in different Pakistani schools. It is the text that determines how effectively the critical thinking and knowledge is being developed in the learners. Both critical thinking and knowledge are the need of students at secondary level and these skills are essential for the English Language classrooms. These skills enable the students to learn concepts more thoroughly and without this learning outcome cannot be achieved. The questions given at the end of chapters of English textbooks (PTB) and (OPE) have been qualitatively analyzed. The proposed model of critical thinking used by Janpha Thadphoothon (2005) has been employed in this study. The findings of the content revealed that both text books contained the elements of critical thinking helpful in enhancing the knowledge of the students. The PTB textbook covers $25.37 \%$ and OPE covers $43.18 \%$ of critical thinking content for the secondary students. The findings revealed that the textbook published by OPE is playing a more significant role in developing critical thinking and enhancing knowledge in the students as compared to the PTB textbook.
\end{abstract}

Key words

Critical Thinking, Knowledge, English Language Classrooms, Text Books, English Language Learners

\section{Introduction}

During the final decade of $20^{\text {th }}$ century critical thinking became a focus in the area of second and foreign language (L2) education as a critical education provides the means and skills important for independent thinking and knowledge (Paul, 1993, p. 227). Critical thinking skills apply within and beyond the formal education contexts, these skills enable the students to assimilate subject specific course content more thoroughly and also provide a framework that allows them to engage with and respond to problems they may confront during their lives (Tsui 2002). The proficiency to think critically is seen as a core academic skill due to its importance in learning process (Paul 2005). Ten Dam and Wolman (2004) value critical thinking as a crucial aspect of competence that citizens need to participate in a pluralistic and democratic society, it enables them to make an individual contribution to their society. Critical thinking helps to discover deep knowledge hidden inside a text.
With our significantly changing world in the $21^{\text {st }}$ century, it has become very important for our students to be critical thinkers. Critical thinking enables the learners to learn thoroughly subject specific course content. English has become an international language(Akhter, 2020).In English, the domain of language learning and critical thinking enables the learner to go beyond the word or sentence and find out the hi Edden meanings of the text. Critical thinking has its great importance in English textbooks as it develops a series of abilities that take students beyond simple comprehension of information.

The basic purpose of critical thinking is not to criticize the text, the author or the literary qualities of that author's era. Rote learning is a widespread strategy practiced by the students of Pakistan. There are mostly two strategies of learning: surface learning approach and deep learning approach. The surface approach is memorizing the information without understanding the deeper knowledge, and also known as rote learning; whereas in the deep approach, students engage themselves in the study process to hold the deeper understanding of the 
content (Duff, Boyle, Dunleavy, \& Ferguson, 2003).

Critical thinking is not a new area of research it has been investigated across various nations including the United States (Association of American Colleges and Universities 2004), Australia (Tapper 2004), China (Tian \& Low 2011), Iran (Fahim \& Saeepour2011), and Singapore (Lim 2015). English is the official language in Pakistan and it is need of every individual to develop the ability to analyze the language in such a way that he/she can understand the meaning. As the English language has become so common in different areas of life that it is considered a crucial aspect for the people that they should have the skills to think critically in their mother tongue and not only in their mother tongue but also in English. Now-a days, a significant change has been observed in the learning and teaching of English language and the change is that major stress is given to multi word units rather than individual words(Xu, Akhter, \& Qureshi, 2020).

English is an international language and English Language teaching has become important because of the global status of English. English Language teaching is a technique that needs great efforts on the part of all the participants. The textbooks are the very important element of teaching process for the aims and objectives of a course and these textbooks and ways of teaching develops critical thinking and knowledge in learners.

In Pakistani context, both knowledge and critical thinking are important for the students of secondary level. Critical thinking abilities are becoming increasingly important in existing society and job flea because of emerging technologies and the great amount of information at hand. As prospective EFL (English as a foreign language) teachers it is important for us to recognize the significance of critical thinking skills and how to improve them in our students as well as teachers. The teacher feels difficulty in developing their own classroom material, have a limited time and lie under external pressure that cramp their abilities and this is the reason that not only students but teachers also do not have critical skills (Obaid 2016). In UK, the modern educational philosopher Barnett (1990) said that, if there is a single key concept in the idea of higher education, it is criticism. As language teacher in Pakistan, it is responsibility of teacher to improve student's critical thinking competence. It is the reality that different students may have practiced varying degrees of nurture or disappointment at the hands of their parents, earlier education, and wider culture. There is difference between student level of critical thinking and language and the level of critical thinking of our student may not be linked to their language level. The teacher can take start by introducing tasks in which ask students to question what they read and listen and investigating the deeper, more hidden meanings in the texts and characterize assumptions and weaknesses.

\section{Statement of the Problem}

The teaching of critical thinking is claimed to be increasing in English language classrooms but not according to the requirement of the students (Ilyas, 2015).There are two advantages to critical thinking's amalgamation in ELT (English language teaching). First, it can expand learner's language abilities and second, it can encourage and expand their critical thinking abilities. It is because; in this context English language learners would be asked to think in their target language. Hawkins (1998) sees the incorporation of critical thinking into ELT from a different point of view and states that not teaching critical thinking to English language learners' results in preventing them from achieving success. Teaching English language learners only the language skills, without critical thinking skills, equates to backing linguistic imperialism (Ilyas, 2015). A textbook according to the need of a student is important and it is the textbook that generates critical thinking skills among the students. Pakistani textbooks have been changed several times but the pattern of textbook is still same for the students. The activities that lead the student to become a critical thinker are not included in the textbooks. The textbooks are taught by the teachers in traditional way leading to the fact that they are not able to develop critical thinking in the students. There have been few studies conducted on critical thinking in English language classrooms. The present work shows that particularly no research conducted on critical thinking in Pakistani school English textbooks. In every part of the world, speakers and learners of English can be seen. For non-native speakers of English, the practice and handling of Idiomatic expressions is very important (Wang, Akhter, \& Qureshi, 2020). 


\section{Objectives}

The objectives of the study are:

- To analyze the content of textbooks is knowledgeable for the learners.

- To analyze the textbooks have the potential to develop Critical thinking of learners in English language Classrooms.

\section{Research Questions}

The Study endeavors to address the following research questions:

1. What sort of knowledge is provided to the learners of secondary level through English textbooks published by Punjab Textbook Board and Oxford progressive English?

2. How do the questions asked at the end of chapters in Oxford and Punjab textbooks foster critical thinking?

\section{Literature Review \\ Meaning and Scope of Critical Thinking}

A broad range of definitions in literature provide variety of views on critical thinking. According to Oxford dictionary (2015) critical thinking is, "The objective analysis and evaluation of an issue in order to form a judgment", whereas according to Davies and Barnett (2015), "critical thinking is about having skills of a certain sort" ( $p$. 7). Paul and Elder (2006) defines problem-solving "the process of reaching solutions" (p. 58), and creative thinking as, "resulting from originality of thought" (p. 14). There is contradiction observed in the literature review about creative thinking and critical thinking. Whitehead (2004) considers creative thinking and critical thinking as two separate modes of thought while Paul and Elder (2004) conclude them to be inseparable. For Cottrell (2005), learning to think in critically analytical and evaluative ways means using mental processes such as attention, categorization, selection, and judgment. Analysis, implication, synthesis, evaluation, application and use of skills to plan the outcome in a situation are seen as fundamental for critical thinking. Brookfield (2008) ascertains that students can be taught to recognize and use skills appropriately and make their thinking more effective.

Higher education aims to prepare graduates with critical thinking skills to deal with unseen complex realities. Gardner (2009), emphasize that education must raise human understanding about who we are and what we can do. This is like Barnett's (1997) theoryof 'critical being' and 'critical doing'. Barnett (2015) explain critical thinking as basically collaborative in character, and fixed in interventions in the world of achievement, when understood as a practice. When students in academic learn to look through things (Nosich, 2012) through their critical thinking skill, they develop critical view (Barnett, 1997) a critical capacity oriented to the world of knowledge. Critical thinking is therefore naturally a matter of degree and dependent on other things the quality and intensity of experience in a given realm of thinking or with respect to a specific class of questions. No one is a critical thinker through, but only to a certain degree, with particular insights (Paul, 1993).

Role of Textbook in developing Critical Thinking

The modern teaching methodologies like communicative language teaching and task based language teaching (English speaking countries) have trim down the task of course books for language teaching in these countries. On the other hand textbooks or language course books still perform a crucial role and function as a part of the curriculum in non-English speaking countries (Holliday, 1994). The textbooks to be used present a structure to the curriculum and too bring consistency and normalization in the training so that the learners studying in different institutes working under the same education scheme may receive similar content and be tested the same way. Well-prepared textbooks are also very valuable for the English language teachers. They may save teachers from the affliction of material designing and make possible for them to devote their time to teaching. Fredriksson and Olsson (2006) conducted a qualitative research to investigate criteria for selecting the English textbooks. They examine how English teachers in one definite upper secondary school solve the assignment of selecting English textbooks. The results revealed that most important criterion to consider in the selection is according to the teachers, motivating and relevant texts that the students can narrate to. Varying and motivating texts are important for both the teachers and students. Perveen (2011) also conducted her study to evaluate the curriculum at the primary level in the light of education policies and plans in Pakistan. Results revealed that the objectives of curriculum were not fully achieved. The procedure 
of the implementation of policies and plans regarding curriculum remained weak.

Enmis (1998) Critical Thinking Skills

Ennis (1998) developed on influential conception of critical thinking with a detailed list of skills and dispositions that critical thinking entails. His early conception of critical thinking dealt solely with the cognitive dimension. According to Ennis (1962, p.83), critical thinking was the correct assessing of statements. In his subsequent framework of critical thinking, (Ennis 1998) proposed that critical thinking skills comprise:

1. Focusing question

2. Analyzing argument

3. Asking and answering questions for clarification

4. Judging the credibility of a source

5. Observing and judging observation reports

6. Deducing and judging deduction

7. Inducing and judging induction

8. Making value judgments

9. Defining the terms and judging definitions

10. Defining terms and judging definitions

11. Identification assumptions

12. Deciding on an action

13. Interaction with others

\section{Developing Critical Thinking in English Language Classroom}

Elena and Lourdes (2013) find out in their research that lesson planning plays an important role in the development of critical thinking in English language classrooms. They find out that lesson plan is provided to explain the application of critical thinking strategies in ELT. Every teacher heard in their teaching career about the term critical thinking. Critical thinking requires active learning from a student and it does not involve passive learning. Students learn sound knowledge in active learning and can improve their knowledge. It is difficult for the teachers to address critical thinking in lesson plans. If we want to develop critical thinking in our foreign language classrooms it is important to include some specific lesson components in lesson plan. These components are prerequisites, instructional objectives and assessment. Elena Lourdes (2013) finds out in their research that lesson plan is provided to explain the application of critical thinking strategies in ELT. According to Daud and Hustin (2004) critical thinking in language classrooms consider to promote, motivate and stimulate language acquisition and language competence of student also increase. In language learning process, student learns many new words and vocabulary of the student increase and this increase in the vocabulary helps the person to communicate in a good way. Communication is something that helps the students to develop critical thinking and also increase knowledge.

Four areas of language that are important when it comes to critical thinking

1. Word choice

2. Ambiguity

3. Definition

4. Intensity

\section{Research Methodology \\ Research Design of Present Study}

This study focuses on critical thinking skills in English textbooks and analyzes questions given at the end of chapters. This analysis is carried out by applying the proposed model of critical thinking used by Janpha Thadphoothon (2005). At first, the researchers give a general description of questions of given chapters by focusing on content that how far they are helpful in developing critical thinking skills and improving knowledge. The focus will remain on critical thinking skills and improvement of knowledge in English language classrooms. It would be checked whether OPE or PTB textbook (first two chapters of each) is helpful in developing critical thinking and improving knowledge.

\section{The Qualitative approach and its}

appropriateness to study

The employment of qualitative research is appropriate to this study; it investigates how students of English language classrooms understand critical thinking and how this textbook is helpful in developing critical thinking and enhancing knowledge. The understanding of participants of critical thinking explored with the help of questions given at the end of chapters of selected books. Qualitative approach is best to answer the research questions of this study. Content analysis is helpful in focusing on true content and aim of content analysis is to study themes, words, concepts, phrases that are present. In this research, researcher has opted content analysis as a tool. It is helpful in finding the critical thinking skills and improving knowledge.

The Proposed model of Critical thinking 
The data is analyzed under the model Proposed model of critical thinking in Language learning. Critical thinking in language learning that has three major aspects: (1) communication, (2) reasoning, and (3) self-reflection. The three features of the proposed model interpreted into five elements. For practical reasons, some elements are sub-headings in the diagram (under Communication) and others (reasoning) are headings. From the above figure it is clear that five key components are considered important to critical thinking in language learning that are:

1. Linguistic conventions

2. Audience

3. Aims

4. Reasoning,

5. Self-reflection.

\section{Data Analysis}

\section{BOOK 1 (OPE)}

4.1.1 Questions given at the end of chapter 1 are:

1. Write down three ways in paragraph 1 in which the writer tells you that Aloo felt alarmed and frightened as she approached her hut.

2. Explain who Anyango, Ouma and Akoth are. (Paragraph 2).

Why was Aloo so sure that some misfortune had befallen the children? (Paragraph 2)

3. What made Aloo certain that one of her children had met with fate? ( line 20 )

4. Explain why Aloo whispered the words "What had happened to my baby?" rather them saying in a louder voice. (Line23)

5. Explain exactly what had happened whilst Aloo was out weeding the beans and in what way her baby was in danger. ( paragraph 4 )

6. In what way do you think the snake moved when it crawled like a ghost? ( line 35)

7. Why did Aloo lash out with harsh words at the men outside the hut? ( paragraph 5 )

8. Select five abstract nouns or adjectives to describe how Aloo felt in paragraph 5 and 6. Explain how she showed each of the quality you have selected.

9. Explain exactly why Aloo had only a few seconds in which to rescue her baby. (Paragraph7)
From given questions, question no 1 in which writer asked to describe it in three ways that

Aloo felt alarmed and frightened and to answer this question read paragraph

Aloo hastened her steps. She felt nervous and panicky. It looked as though the earth under was moving in the way that angry clouds race in the sky when it is going to rain. But now the earth was moving in the opposite direction pushing the hut further and further away. She started running. The distance was narrowing. She could see more people gathered in the yard close to the hut. She recognized the wife of her brother-in-law, whose hut was in the village next to theirs. Aloo's knees suddenly went weak and numb, and she could not run.

To answer this question 1 , a student read the above mentioned paragraph as answer is not obvious. If we want to foster quality thinking we do not implement things on the students. We want them to try things out on the basis of evidence. To answer this question, a student will read it as the answer is not obviously mentioned in the paragraph and he might be able to develop critical thinking and it will also be helpful in improving knowledge.

In question 2, there are two parts of a question from which part 1 has no critical thinking in it for a student but the second part of a question plays its role in developing critical thinking as it involve reasoning and self-reflection from a student.

Idioms like Met with fate given in Question 4 and Crawled like a ghost given in Question 7 are also helpful for the learners to develop critical thinking. Idioms are a good source of developing critical thinking and in enhancing knowledge because idioms convey hidden meanings e.g. yes one of her children met with fate (line 20). To answer the idiomatic questions a student has to focus on deep structure of the sentence. When Aloo came she saw people gathered outside her house. Anyango, nurse of children was outside the house. Her little child was inside where the snake was found. This idiomatic sentence conveys the meaning that everybody lost the hope and that the kid was in danger.

In question $6,8,9 \& 10$, there is no involvement of reasoning and self-reflection. The answers to these questions are obvious for a student. These questions are not helpful in developing critical thinking skills because of the 
reason that answers are very obviously mentioned in the text, and also they are not fulfilling the requirements of the proposed model of critical thinking presented by JnaphaThadphoothon (2005). A Student will not focus on the deep structure of the text. There is nothing new in this story for the students so that they could improve their knowledge or add something new to their knowledge.

Out of the 10 questions from chapter No 1 , there are three questions that are helpful for a student in developing critical thinking because these questions require reasoning and selfreflection from a student. Remaining seven questions provide a good knowledge to a student as there are new words to acquire so that a student can add new words to his vocabulary.

4.1.2 Questions given at the end of chapter 2 are:

1. Explain the way in which the boy Francis become about as absent as a present personcould be when he was reading. (Paragraph1)

2. How can you tell that Francis was escaping from life when he was reading? Quote some Phrase to support your points. (paragraph 1)

3. Describe the symptoms of mumps which Francis experienced at school. (paragraph 2)

4. What does the writer remember about those days at home when he had mumps? (Paragraph2)

5. Explain the progress which Francis made with his reading in paragraph 3.

6. What were the holes in the text which Francis came up against in his reading and how did he deal with them? (Paragraph4)

7. For which two reasons did Francis particularly enjoy Swallows and Amazons?

8. Describe the variety of books which Francis could choose from the library (paragraph 6).

9. Explain in your own words what it was that Francis wanted most of all from books. (Paragraph 6)

\section{Analysis}

Question 1\& 2 have the potential to develop critical thinking in the students and both questions demand reasoning from a student without reasoning answers cannot be delivered by a student. Francis is a little kid, but when he starts reading, he forgets everything around him just like an experienced reader. Reading is the base of critical thinking and knowledge as well and deep reading leads a student to become a great critical thinker.

In question 3 , the answer is obvious for a student. No self-reflection is required to answer the question. In question 4,again no reasoning is required from a student. A student will just read the paragraph and answer the question. In question 5, no deep thinking is required as answer is obvious for a student. The proposed model of critical thinking presented by Janpha Thadphoothon (2005), states at appropriate reasoning means there is balance between logic and ethics. In question 3, $4, \& 5$, no logical answers required from a student and after casual reading of the text, a student can easily explain the answers of these questions.

Question 6, however,involves self-reflection of a student. To answer this question, a student will have to read the whole paragraph and answer is not clearly mentioned in the paragraph so he will have to make inferences. In question 8, the concepts under discussion can be easily found in the suggested paragraph. Hence, no particular reasoning or self-reflection is required from a student.

In question 7, although reasoning is required but after reading the mentioned paragraph in the question, a student will be able to answer the question because the answer is explicated stated. In question 9, self-reflection is required from a student to answer the question. To answer the given question, reading of full chapter and not only casual reading but deep reading is required. The proposed model of critical thinking presented by Janpha Thadphoothon (2005), states that self-reflection allows us to be more objective and open minded.

Out of the 9 questions, there are 4 questions that will help the students in developing critical thinking as these questions require reasoning and self-reflection on the part of a student. Without both of these two elements of the proposed model of critical thinking by JnaphaThadphoothon (2005), answers cannot be explained by a student. While the other questions are concerned, they are only a good source of knowledge. These questions give the direction to the readers, on how to utter those words that are new for the reader.These questions provide a guideline to the beginners who may feel difficulty to start reading English textbook.

\section{BOOK III (PTB)}

4.2.1 Questions given at the end of chapter 1 are: 
1. What happened when Abu jehl asked about Hazrat Abu Bakr(R.A)?

2. Why was Hazrat Abu Quhafaa (R.A)worried?

3. How did HazratAsma(R.A) console her grandfather?

4. Who was Hazrat Abdullah bin Zubair (R.A)?

5. Which incident in the story showed HazratAsma's (R.A) love and respect for the Holy Prophet (R.A)?

6. Which incident in the story tells about the generosity of HazratAsma (R.A)?

7. What message do you get from the life of HazratAsma (R.A)?

8. She lived a life of hardships but never swerved? Comment.

\section{Analysis}

Question 1, 2,3,4,5, \& 6, are a good source of knowledge for a student because life incidents of Hazrat Asma (R.A) are described in the text of these questions, but these questions are not appropriate for the development of critical thinking in the students as these questions cannot be analyzed under the proposed model of critical thinking used by Janpha Thadphoothon (2005) in his study. These questions do not play role in developing critical mind among students.

Question $7 \& 8$,are good for the students in the development of critical thinking because these questions requires self-reflection of a student. According to the proposed model of critical thinking these questions allows the students to become more objective.

Out of 8 questions, 2 questions are effective for a student in the development of critical thinking because these 2 questions are appropriate according to the proposed model of critical thinking. Remaining questions provide good knowledge to the students. This chapter provides the knowledge to students regarding life incidents of Hazrat Asma (R.A).

4.2.2 Questions given at the end of chapter 2 are:

1. What led the author into designing web pages and graphics? How was it Beneficial for him later? 2. What has helped the author to gain valuable commercial experience?

3. What was the author's inspiration for his painting?

4. How is playing cricket a welcome break from normal study for the author?

5. Which activity helped the author use his communication skills?
6. Why is it important to keep balance between curricular and co-curricular Activities?

7. How are co-curricular activities helpful in learning life skills?

Analysis

In question $1,2,3,4,5, \& 6$, answers are explicitly mentioned in the text of chapter. These questions are not suitable for the students in development of critical thinking as these questions are not appropriate according to Theproposed model of critical thinking. Casual reading is required from a student but this reading is not helpful in developing critical thinking of a student. All these questions cannot be analyzed under the proposed model of critical thinking used by Janpha Thadphoothon (2005), as these questions do not wants reasoning and self-reflection from a student. In question 7 , self-reflection of a student is applicable. Without this element of the proposed model of critical thinking answer cannot be explained by a student. This question is playing its role in developing critical thinking in a student as it involves self-reflection of a student.

Out of 7 questions, 1 question is beneficial for the students in developing critical thinking as only one question can be analyzed under the proposed model of critical thinking used by Janpha Thadphoothon (2005).The answers of above mentioned questions are related to co-curricular activities. These activities play an important role in making student physically active. It brings the students out from their desks and enables students to experience new things. Co-curricular activities are helpful in bringing critical thinking skills in students. Experience of new things added something to the knowledge of student and also play role in developing critical thinking skills. No one can deny the importance of Co-curricular activities in developing critical thinking and improving knowledge of the student.

\section{Over all Analysis of textbook}

Sixty-seven questions are present at the end of chapters and seventeen questions are effective for the students in developing critical thinking. These seventeen questions are appropriate according to the proposed model of critical thinking used by Janpha Thadphoothon (2005) first time in his study.

Remaining questions impart knowledge to the students. Although very familiar concepts discussed in this textbook but add something new to the knowledge of the students. 
Comparison of selected Books

The research Questions of this research are

1) What type of knowledge is provided to learners by Questions at the end of chapters Of English textbook published by OUP \&PTB?

2) How much Critical thinking is developed among the learners at secondary level through Questions asked at the end of chapters in Oxford and Punjab textbook?

To answer the research questions, researcher focus on Questions asked at the end of chapters. From point of view of knowledge, Oxford progressive English textbook is a good source. The language used in this book is difficult for the students, but if student study it with interest he can add lot of new concepts to his knowledge. New collections of words for students are available in this textbook. There are lots of things added in the exercise at the end of every chapter that add lot of things in student knowledge. The second textbook PTB, although knowledgeable for the students but concepts are very easy casual. Simple language is used in the text and not more vocabulary items are included in it.

From the view point of critical thinking, OPE book involve reasoning and self-reflection in it. And according to the proposed model of critical thinking used by Janpha Thadphoothon (2005), first time in his study states that logical reasoning and self-reflection of a student, creates critical mind and also improve knowledge of a student.

This book requires deep reading from a student to answer the given question at the end of chapters and the students are not able to answer the question, if he will only focus on surface structure of the text. The concepts are not apparently mentioned, they are deep insight. There are some concepts added like (Co- curricular activities) that enable student to think critically. In the second textbook PTB, concepts are on surface structure of the text and involvement of critical thinking is less for a student as it could be.

Chapters are organized in a good way in both the textbooks. There is proper start and end of the chapters. Both the textbooks contain learning objectives in the start of every chapter. Vocabulary items are included at the end of chapters in both textbooks. Both the textbooks involve some activities in the exercise of every chapter.

\section{Discussion}

Critical thinking and knowledge both are important for the students of secondary level. Both these inter-related competencies are need of the students. The results of one variable cannot be achieved if a student does not have the second one. This is the first step of students toward their career. If at this level students do not acquire proper knowledge they may find difficulties in their future. This present study attempts to investigate that how much these skills students are acquiring with the help of questions given at the end of text book chapters. There is research studies conducted on the issues of critical thinking in English language classrooms but particularly on this topic no research study has been conducted in Pakistani context. Being a researcher, I found this gap. To explore this gap was the need of students.

Questions play their role in enhancing the knowledge of the students. A student learns new things, ideas, words, phrases. There are new words of vocabulary in the text for students. Knowledge is essential for the students. Some questions include deep reading and without reading answers cannot be explained by a student. It is a fact that reading is a key that increase knowledge of the students. Concepts learn at this level are the essence of life of a student. Teacher's subject knowledge is important and it plays very important role in enhancing knowledge of the student. If teacher is knowledgeable, he is able to deliver new things to the students. Teacher should use different strategies in his teaching so that students can easily understand and learn new concepts and increase their knowledge.In start difficult things are not easy to learn for the students but if once students develop habit to learn difficult things, he can surely increase his Knowledge.

Students can easily learn through collaboration: collaboration with peers, teachers and in the groups. Social interaction was essential for the students in their preceding courses as well but they were not given the chance to learn through activities which provide opportunities to the students to collaborate with their fellow students and teachers. The practice of interaction in a classroom is not encouraged in Pakistan where the 'best' classroom is where there is pin drop silence (Mehmood and Manan, 2015).

OPE book is knowledgeable for the learners and this textbook is helpful in developing critical thinking in the students. Although questions given at the end of chapters are less in number that help 
the student to develop critical thinking but some questions in every chapter are useful in developing critical thinking. Reasoning and self-reflection of a student involve in the questions that leads the students to develop critical thinking.

In PTB, questions given at the end of chapters are sixty-seven. From these questions there are approximately seventeen questions that help the students to develop critical thinking according to the proposed model of critical thinking. Questions given at the end of chapter are common and these questions do on include deep reading of the text. The concepts are apparently present in the text of chapters.

Knowledge is something that helps the students to go ahead in their life. In this book, questions given at the end of chapter are common. Concepts are new but common for the students. These questions lead the students to increase their knowledge. Vocabulary that is used in the textbook is quite simple.

With the teaching of critical thinking gaining popularity in education and especially in English language classrooms, the field of ELT has begun to include it. There are at least two advantages to critical thinking's incorporation in ELT. First, it can improve learners' language proficiency.

Second, it can promote and improve their critical thinking skills. This is because in this context, English learners would be asked to think critically in their target language.

The results of present study show that the Pakistani ELT textbooks, especially those for language study programs, contained literary works such as folktales, short stories, poetry, song lyrics and play scripts. Though there are not many questions facilitating students' critical thinking in the textbooks. The findings of the current study show that the Pakistani English textbooks used by secondary schools contained literary-based questions, and some of these questions do facilitate students' critical thinking skills. It can be assumed that the textbooks have provided the foundation for the development of students' language proficiency and critical thinking skills. Therefore, the present results are significant in at least major two respects. Firstly, the literary works contained in the textbooks could be used to develop Pakistani students' English proficiency. Secondly, the works can also be used to encourage the students' critical thinking skills

\section{Conclusion and Recommendations}

This research is conducted on the topic Study of critical thinking and Knowledge at secondary level. The two textbooks OPE \& PTB were analyzed in this regard. Questions given at the end of chapters are analyzed. The purpose of this study is to examine that to which extent they are helpful for English language students in developing critical thinking and enhancing knowledge. Qualitative approach is used in this study. Both textbooks are taught in different schools of Pakistan in Punjab. PTB is used in most of schools of Punjab and the second book OPE is specific for O level students. Both textbooks are playing their role in developing critical thinking and knowledge. PTB book is some extent easy as compare to OPE book. Although both textbooks play their role in developing critical thinking and knowledge but it is a fact that one textbook contains difficult material in it and in the second textbook common concepts are given. The findings of this study show that OPE book is good for the students as compare to second textbook. This textbook deals in a good way with critical thinking and knowledge. This is the learning stage of students and habits developed at this age. If at this level, students make their habit to learn difficult things it will helpful for them in their life. But if at this age, student develop habit of easy learning it will create difficulty for students in their life. For the student of this level reading is essential. Reading is the path that makes able to his reader to develop skills of critical thinking and enhancing Knowledge. If student of this level is enabling of deep study, student is able to go beyond the sentence, he is capable of having critical thinking skills and having sound knowledge.

In English language Classrooms having skills of critical thinking are very important. Without this student is not able to make his concepts clear. In questions usually answers are not obvious on the text of chapters. There are some questions in which answers are not on surface structure. Such questions are present in both the textbooks. In short it is concluded that role of curriculum is very important. It is the responsibility of such Panel that is involved in designing of curriculum. Curriculum should be according to the needs of students.

Observing the limitations of the current study, more work will need to be carrying out in the following areas:

1. Research is needed on how Pakistani school teachers perceive critical thinking and how 
teachers use the textbooks in English language classrooms.

2. Further study can be conducted to analyze organization of chapters given in the start of textbooks that whether teachers are following it or not. And is this organization is helpful in achieving aims of critical thinking or not.

3. A research can be conducted on the other English textbooks that are being taught by teachers at vocational schools that whether they are enhancing critical skills among students or not.

4. Last but not the least, future studies can apply ABC model or Proposed of critical thinking to find out critical thinking skills in Language classrooms.

5. Apart from contesting ideas through practicing critical thinking, a future study may propose the kind of critical thinking required in Indonesia.

\section{REFRENCE}

1. Akhter, S., Qureshi,AH.,Hassan,MU.,Tanveer,B. (2020). Deconstructing Issues of Identity in the Reluctant Fundamentalist by Mohsin Hamid. AL-ADWAH', 35 (1), 1529.

2. Barnett, R. (1997). Higher education: a critical business. Buckingham, England: Open UniversityPress.

3. Barnett, R. (2015). A Curriculum for Critical Being. In M. Davies \& R. Barnett (Eds.), The Palgrave handbook of critical thinking in higher education (pp. 63-77). New York, NY: Palgrave Macmillan.

4. Brookfield, S. (2008).Developing critical thinkers: Challenging adults to explore alternative Ways of thinking and acting. San Francisco, CA: Jossey-Bass Publishers.

5. Cottrell, S. (2005). Critical thinking skills: Developing effective analysis and argument. New York, NY: Palgrave Macmillan.

6. Davies, M., \& Barnett, R. (Eds.). (2015). The Palgrave handbook of critical thinking in higher education. New York, NY: Palgrave Macmillan.

7. Elder, L. \& Paul, R. (1998). The role of Socratic questioning in thinking, teaching, and learning, The clearing House: A journal of Educational strategies, Issues and Ideas, 71(5), 297-301.

8. Ennis, R. H. (1998). Is Critical Thinking Culturally Biased?Teaching Philosophy, 21(1), 15-33.

9. Fredriksson, M \& Olsson (2006). A taxonomy of problem-based learning methods. MedicalEducation, 20, 481-486.

10. Fahim, M. \&Sa'eepour, M. (2O11), The impact oteaching critical thinking skills on readingComprehension of Iranian EFL learners, journal of language teaching and research, 2(4), 867-874.

11. Gardner, H. (2009). Multiple approaches to understanding. In K. Illeris (2nd Ed.), Contemporary Theories of learning: Learning theorists in their own words (106-115). New York, NY:Routledge.

12. Ilyas, H. (2015). Critical thinking: Its Representation in ELT Textbooks and Education. University of York Education

13. Klikauer, T. (2015).Adorno's ends of philosophy and the future of critical theory.Capital \& Class, 39(2), 373-379. Retrieved September 19, 2018 http://doi.org/10.1177/030981681558519 8

14. Manan, S.A. and Mehmood, T., (2015). Culture and Critical Thinking in Classroom: Narratives from University Students in Pakistan. Asia Pacific Journal of Social Science, 1(3), 110-134.

15. Nosich, G. M. (2012). Learning to think things through: A guide to critical thinking across the Curriculum (4th Ed). Boston, MA: Pearson.

16. Obaid, R, (2016). An Evaluation of the second intermediate Saudi English Language textbook from the teachers point of view. Advances in Language and Literary studies, 17(2).

17. Paul, R. (1993). Critical thinking: what every person needs to survive in a rapidly changing World (rev. 3. Ed). Santa Rosa: Foundation for Critical Thinking.

18. Paul, R., \& Elder, L. (2006).Critical thinking: learn the tools the best thinkers use. UpperSaddle River, N.J.: Pearson/Prentice Hall 
19. Perveen, S. (2011).Thinking critically, thinking dialogically. TESOL Quarterly, 33(3), 573-580.

20. Tapper, P. 2004. Curriculum action research (2nd Ed). London. Kogan Page.

21. Tsui, P.2002. A brief conceptualization of critical thinking.Retrieved August 21, 2018 from http://www.criticalthinking.org/pages/def ining-critical-thinking/410/.

22. Whitehead, D. (2004). Top tools for teaching thinking. Auckland, N.Z.: Pearson Longman.

23. Wang, Z., Akhter, S., \& Qureshi, A. H. (2020). Towards the Description of English Idioms for EFL Learners from Learning and Teaching Perspective. Revista Argentina de Clínica Psicológica, 29(3), 285.

24. Xu, D., Akhter, S., \& Qureshi, A. H. (2020). Towards the importance of English collocations for L2 Learners, A Corpus-Based study. Revista Argentina de Clínica Psicológica, 29(3), 185. 